
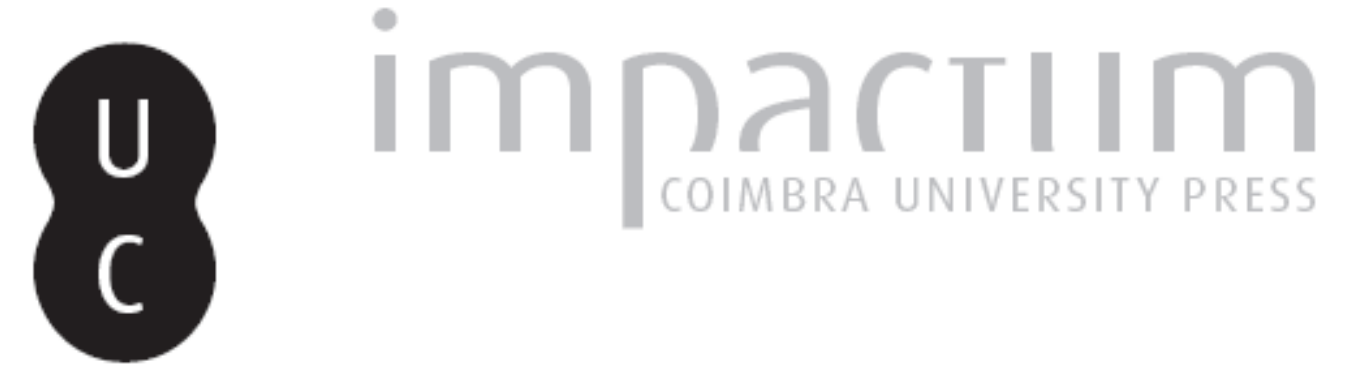

\title{
[Recensão a] Mentalities/Mentalités, revista semestral
}

\author{
Autor(es): $\quad$ C., J. R.
}

Publicado por: Imprensa da Universidade de Coimbra

URL persistente: URI:http://hdl.handle.net/10316.2/45122

DOI: $\quad$ DOI:https://doi.org/10.14195/2183-8925_7-2_34

Accessed : $\quad$ 26-Apr-2023 13:05:13

A navegação consulta e descarregamento dos títulos inseridos nas Bibliotecas Digitais UC Digitalis, UC Pombalina e UC Impactum, pressupõem a aceitação plena e sem reservas dos Termos e Condições de Uso destas Bibliotecas Digitais, disponíveis em https://digitalis.uc.pt/pt-pt/termos.

Conforme exposto nos referidos Termos e Condições de Uso, o descarregamento de títulos de acesso restrito requer uma licença válida de autorização devendo o utilizador aceder ao(s) documento(s) a partir de um endereço de IP da instituição detentora da supramencionada licença.

Ao utilizador é apenas permitido o descarregamento para uso pessoal, pelo que o emprego do(s) título(s) descarregado(s) para outro fim, designadamente comercial, carece de autorização do respetivo autor ou editor da obra.

Na medida em que todas as obras da UC Digitalis se encontram protegidas pelo Código do Direito de Autor e Direitos Conexos e demais legislação aplicável, toda a cópia, parcial ou total, deste documento, nos casos em que é legalmente admitida, deverá conter ou fazer-se acompanhar por este aviso.

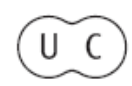




\section{REVISTA DE HISTORIA DAS IDEIAS 7}

\section{REVOLTAS E REVOLUCOẼS}

\section{**}

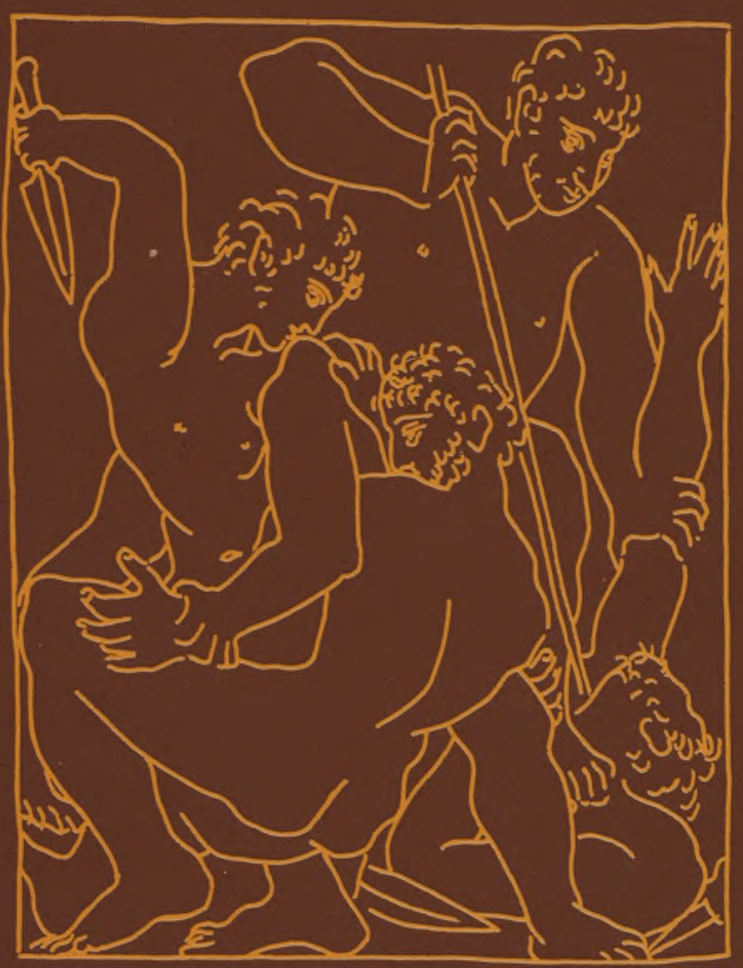

INSTITUTO DE HISTÓRIA E TEORIA DAS IDEIAS FACULDADE DE LETRAS 
néus (lembramo-nos em particular do vínculo vassálico para com o papado). Como cume das hierarquias de vária ordem que ligavam o espaço local ou regional ao espaço europeu teria pleno cabimento na segunda parte (composição) ou inaugurando um terceiro plano de análise, que permitiria enquadrar melhor os anteriores e, estamos certos, traria novos argumentos para algumas das conclusões do autor.

\section{António Resende de Oliveira}

Mentalities/Mentalités, revista semestral, Outrigger $\mathrm{Pu}-$ blishers, Hamilton, New Zealand, vol. 2, n.os 1 e 2, 1984.

Mentalities/Mentalités é uma publicação semestral neocelandesa dedicada à história das mentalidades. Os dois números de 1984 distinguem-se do formato habitual das publicações periódicas no campo da história: pouco volumosos (rondando as 50 p.) e repartindo o seu conteúdo por três ou quatro artigos breves e por algumas dezenas de recensões críticas de publicações recentes. A variedade temática é grande, tanto nos artigos como nas recensões críticas: desde o femininismo às religiões da pré-história, passando pela inevitável informática e cibernética. Uma constante contudo: é principalmente o universo científico e académico anglo-saxónico que nos surge nestas páginas. As recensões incidem sobretudo sobre a bibliografia de língua inglesa, e os autores das recensões são oriundos na sua maioria de Universidades Norte Americanas. Assim Mentalities/ /Mentalités torna-se um instrumento útil de contacto com a produção de língua inglesa no domínio da história das mentalidades, geralmente menos acessível entre nós que a produção francófona, sem deixar de ser contudo uma publicação de aspirações «intemacionalistas». Veja-se a lista dos «conselheiros de redação»: Hélène Ahrueiler, Peter Burke, Georges Duby, Richard Hoggart, Hija Konew, Zoran Konstantinovic, Walter Leitsch, Emmanuel Le Roy Ladurie, Hans-Jürgen Lüsebrink, Lloyd de Maus, Adrian Marino, Jacques Marx, Walter J. Ong S. J. e Immanuel Wallerstein. Temos representado (com nomes sonantes) um leque de países variados: França, Inglaterra, Bulgária, Austria, Alemanha, Estados Unidos, Roménia, Bélgica e Israel.

Mas a diversidade dos conteúdos dos artigos e das recensões não deixa de levantar no espírito do leitor a questão sempre pendente da dificuldade de definição do objecto da história das mentalidades. A capa do vol. 2, n. $^{\circ} 1$ de Mentalities/Mentalités 


\section{Recensões}

afirma que a história das mentalidades é uma nova aproximação interdisciplinar dos problemas de história da cultura, das ideias e das instituições. Segue-se uma enumeração sintomática de temas, e cito, traduzindo: «relações entre os sistemas de comunicação e de pensamento e das suas articulações com as instituições domésticas, familiares, públicas ou esotéricas; provérbios, mitos, lendas, vistos sobre os aspectos do discurso do quotidiano, do ritual, da propaganda e dos exercícios pedagógicos; a feitiçaria e as suas implicações sociais, religiosas, jurídicas ou políticas; os esquemas mentais e a praxis; o modo como os comportamentos quotidianos são esclarecidos pelo estudo da criminalidade e pelos processos pelos quais a violência é controlada, diminuída, desviada ou orientada de maneira formal ou informal; o dinamismo dos grupos etários e as suas relações com as organizações profissionais ou regionais; as imagens e os lugares mnemónicos enquanto relacionados com os contornos da comunicação social, estética e política; os modos de viver e trabalhar no espaço, considerando este no plano estético mas também semiótico; um sem número de problemas similares e interrogações visando descrever e compreender «o espaço» tridimensional do pensamento e do sentimento, ou seja, as dimensões do tempo da experiência e dos modelos»».

Esta enumeração não pode aspirar, evidentemente, ao estatuto de «aproximação interdisciplinar». Como dizia Barthes, interdisciplinariedade não é juntar à volta de uma mesa (ou de uma publicação) uma série de pessoas de disciplinas diferentes. Interdisciplinariedade é reunir uma série de pessoas à volta de um objecto comum. Estou certo que outros partilharão da minha dificuldade em simplesmente entender alguns dos objectos da enumeração anterior. $\mathrm{O}$ máximo que podemos reconhecer a esta quantidade imensa de problemas e temas é a existência de uma sensibilidade comum que se situará, eventualmente, no território vago do estudo dos sistemas de signos.

Nã̃o deixará de haver, por isso, quem reduza a história das mentalidades a uma voga recente, provavelmente passageira, uma mistura de moda e de operação de «marketing». As modas podem ser perigosas em ciência, especialmente em ciências humanas: tendem a criar um «estilo», um «calão», que lhes fornece, através de um conjunto de termos e construções preferenciais, uma pseudo-identidade, marca de uma especificidade artificial que nem sempre é possível fundamentar epistemológicamente. Mas as modas não são desprovidas de sentido e significância. A preocupação com os domínios do simbólico, com os sistemas de signos enquanto entidades de estatuto próprio, gozando não só de uma certa autonomia mas até de um carácter fundador dentro das formações sociais, não deixa de revelar a 
insatisfação com modelos de análise mais tradicionais e a fé, nem sempre explicitamente assumida, de uma outra via para o sempre invejado rigor formal das «ciências exactas». Via que passaria agora não só pela contabilização matemático-estatística dos substractos materiais da vida, mas sim pela análise dos sistemas de representação, enquanto sistemas de signos, com toda a aparelhagem estrutural formalizante importada da linguística.

Estes e outros problemas são, aliás, equacionados por Jacques Marx numa «mise au point» de leitura proveitosa a abrir o volume 2, n. ${ }^{\circ} 1$ : «Les Mentalités: Un au-delà de l'Histoire». O mesmo número de Mentalities/Mentalités inclui ainda: «Les Manuels scolaires dans l'école élémentaire victorienne», por Dominique Lerch; «Religion, Ritual and Cosmology: Three New approaches to the history of Eastern Africa», de David Newbury. O segundo volume de 1984 inclui: "Whaikoorero: Some Social and Political Implications of Maori Oratory», por Keith e Ginette Sullivan; «Les Almanachs en Suisse», por Dominique Lerch; «Empiricism and the Phenomenology of Religious Experience», por James J. Preston, e «Beyond Ideology: Apostacy and the Horrors of Selfhhod in Some Renaissance Texts», por Brian Opie.

J. R. $C$. 